\title{
Human DNA polymerase $\kappa$ uses template-primer misalignment as a novel means for extending mispaired termini and for generating single-base deletions
}

\author{
William T. Wolfle, M. Todd Washington, Louise Prakash, ${ }^{1}$ and Satya Prakash \\ Sealy Center for Molecular Science, University of Texas Medical Branch at Galveston, Galveston, Texas 77555-1061, USA
}

\begin{abstract}
Human DNA polymerase $\kappa$ (hPolk) is a proficient extender of mispaired primer termini on undamaged DNA, wherein it extends directly by incorporating the next correct nucleotide, generating single-base substitutions in the process. Biochemical and genetic studies, however, have indicated that, in addition to single-base

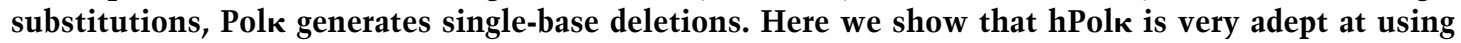
template-primer misalignment as a novel means for extending mispaired termini and for generating single-base deletions. The proficient ability of hPolk to extend mispaired primer termini either directly or by misalignment could be important for the continued and efficient progression of the replication fork when mismatches introduced by the replicative polymerase are not proofread. In extending from nucleotides opposite DNA lesions, hPolk uses the direct and misalignment modes of mispair extension to different extents, depending on whether the template base is present or not at the primer terminus; thus, although hPolk can extend directly from nucleotides opposite damaged bases, it can use only the misalignment mechanism to extend from nucleotides opposite an abasic site. A particularly unconstrained active site at the template-primer junction could afford hPolk the ability to tolerate the geometric distortions of mismatched base pairs or those resulting from template-primer misalignment, thereby enabling it to use both of these modes of mispair extension.
\end{abstract}

[Keywords: DNA polymerase $\kappa_{\text {; }}$ template-primer misalignment; mispair extension; base deletions; translesion DNA synthesis]

Received May 1, 2003; revised version accepted June 26, 2003.

DNA lesions often block replicative DNA polymerases (Pols), and replication through such lesions requires the participation of specialized translesion synthesis (TLS) DNA polymerases. In both prokaryotes and eukaryotes, DNA polymerases belonging to the $\mathrm{Y}$ family are able to promote replication through DNA lesions. DNA polymerase $\eta$ (Pol $\eta$, from both yeast and humans, replicates through a cis-syn thymine-thymine (TT) dimer (Johnson et al. 1999; Masutani et al. 1999), and steady-state kinetic studies have indicated that both these polymerases incorporate As opposite the two Ts of the TT dimer with the same efficiency and fidelity with which they incorporate As opposite undamaged Ts (Johnson et al. 2000c; Washington et al. 2000). Genetic studies in yeast have also implicated Pol $\eta$ in the error-free bypass of cyclobutane dimers formed at $5^{\prime}-\mathrm{TC}-3^{\prime}$ and $5^{\prime}$-CC- $3^{\prime}$ sites (Yu et al. 2001). Poln can promote the efficient bypass of vari-

${ }^{1}$ Corresponding author.

E-MAIL 1.prakash@utmb.edu; FAX (409) 747-8608.

Article and publication are at http://www.genesdev.org/cgi/doi/10.1101/ gad.1108603. ous other DNA lesions as well (Haracska et al. 2000a,b). In addition to Poln, humans contain two other Y-fam-

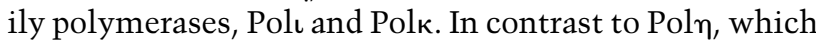
promotes replication through DNA lesions by both efficiently inserting the nucleotide opposite the lesion and by extending from the inserted nucleotide, Polı and Polк promote TLS by promoting either the incorporation or the extension step, but not both (Prakash and Prakash 2002). For instance, Polı can incorporate nucleotides opposite the 3'T of a (6-4) TT photoproduct and opposite an abasic site, but it does not extend from the inserted nucleotide (Johnson et al. 2000b). Polк, originally called Pol $\theta$ by us (Johnson et al. 2000a), on the other hand, functions at the extension step; for example, it can extend from nucleotides inserted opposite the $3^{\prime} \mathrm{T}$ of a TT dimer and from nucleotides inserted opposite $\mathrm{O}^{6}$-methyl guanine, but it is highly inefficient at incorporating nucleotides opposite these DNA lesions (Haracska et al. 2002a; Washington et al. 2002).

Whereas Poln and Polı exist only in eukaryotes, homologs of Polk are present in prokaryotes and eukaryotes, as well as in archaea. These Polк-related polymer- 
ases include the $\operatorname{din} B$-encoded Pol IV of Escherichia coli, and the Dbh and Dpo4 polymerases of the thermophilic archaea, Sulfolobus solfataricus. One characteristic feature of all the Polk homologs is their propensity to generate frameshift errors, particularly single-base deletions. Overexpression of Pol IV in E. coli results in a 1000-fold increase in spontaneous -1 frameshifts (Kim et al. 1997). In an in vitro DNA synthesis assay with Pol IV, single-base deletions and base substitutions were found to occur at a rate of $2 \times 10^{-4}$ and $5 \times 10^{-5}$, respectively (Kobayashi et al. 2002), and in similar assays with Dpo4, these changes occurred at a rate of $2.3 \times 10^{-3}$ and $6.5 \times 10^{-3}$, respectively (Kokoska et al. 2002). Genetic and biochemical studies have also indicated a role for Polk in generating -1 frameshifts in addition to base substitutions. Transient overexpression of mouse DINB1encoded Pol $\kappa$ in cultured mouse cells leads to enhanced spontaneous mutagenesis, with $70 \%$ of the mutations being base substitutions and $\sim 30 \%$ of the mutations being single-base deletions (Ogi et al. 1999). In an in vitro DNA synthesis reaction, human Polk (hPolk) generated single-base substitutions and deletions at a rate of $\sim 7 \times 10^{-3}$ and $\sim 2 \times 10^{-3}$, respectively (Ohashi et al. 2000a).

Deletions in homopolymeric runs could occur by the classical Streisinger model (Streisinger et al. 1966), resulting from the slippage of the primer and template strands relative to each other. This mechanism, however, does not explain the large fraction of deletions that occur in noniterated sequences in DinB-related polymerases. Two additional mechanisms, dNTP-stabilized misalignment (Efrati et al. 1997) and misinsertion misalignment (Kunkel and Soni 1988; Bebenek and Kunkel 1990), have been proposed to account for -1 deletion formation in noniterated sequences (Fig. 1). In dNTP-stabilized misalignment, the templating base becomes misaligned ("looped out") in the polymerase active site, and the misalignment is stabilized by the pairing of the incoming dNTP with the complementary next template base (Fig. 1A). The evidence for the formation of -1 deletions by such a "dNTP-stabilized" misalignment mechanism is provided by the ternary complex of Dpo4, where, in type II crystals, the template base $\mathrm{G}$ becomes extrahelical and the incoming ddGTP bypasses this extrahelical base and pairs with the next template base C (Ling et al. 2001). Additionally, these structural data are supported by spectroscopic evidence showing that a template $2 \mathrm{AP}$ becomes extrahelical when Pol IV incorporates a dGMP opposite a template $\mathrm{C}$ located immediately downstream of the 2AP (Kobayashi et al. 2002). Misinsertion misalignment frameshifting occurs when nucleotide misincorporation is followed by template-primer slippage, and this results in the repositioning of the misincorporated nucleotide opposite the next complementary template base (Fig. 1B; Bebenek and Kunkel 1990). However, there has been no evidence that such a mechanism is used by any of the DinB-related polymerases.

Most DNA polymerases, including the replicative polymerases, yeast and human Poln (Mendelman et al. 1990; Goodman et al. 1993; Washington et al. 2001a), as
A

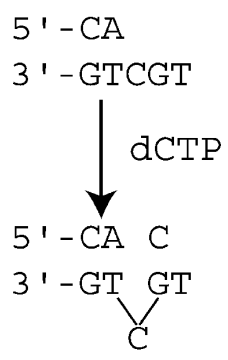

B

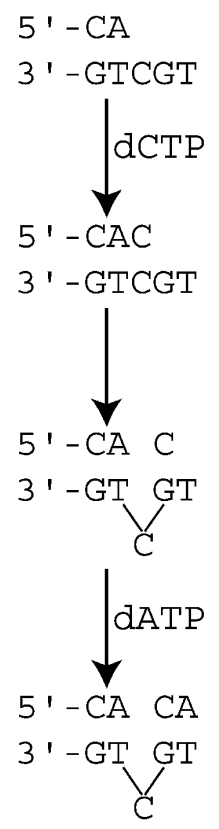

Figure 1. Model for generation of DNA polymerase-dependent single-base deletions. (A) In dNTP-stabilized misalignment, the templating base "loops out", that is, is extrahelical, and the resulting misalignment is stabilized by the pairing of the incoming dNTP with the complementary next template base. $(B)$ In misinsertion misalignment, nucleotide misincorporation is followed by template-primer slippage and the repositioning of the misincorporated nucleotide opposite the next complementary template base.

well as human Polı (Vaisman et al. 2001), extend a given mispair with nearly the same kinetic efficiency as the efficiency of incorporating the incorrect nucleotide to form that mispair. hPolк, however, is more adept at mispair extension than at mispair formation (Washington et al. 2002). In this regard, hPolк differs strikingly from $E$. coli Pol IV, as Pol IV extends mismatches far less efficiently than hPolk (Kobayashi et al. 2002).

Here we show that mispaired primer termini can be extended by hPolк with nearly equivalent efficiencies, either by direct extension or by the realignment of the mispaired primer-terminal base with the next complementary template base. Hence, hPolk could contribute to rescuing the stalled replication fork when primerterminal mismatches are not removed by the proofreading activity of Polo. Such a mismatched primer end could then be extended by hPolk either directly, by incorporating the next correct nucleotide, resulting in base substitution mutagenesis, or, by misalignment of the template base and the pairing of the primer-terminal base with the next complementary template base, resulting in -1 deletion formation (see Fig. 1B). The ability of hPolk to efficiently use such a template-primer misalignment mechanism provides for a novel means of extending mispaired termini and for generating single-base deletions. 


\section{Results}

Extension of mispaired primer termini by hPolk by template-primer misalignment and by the incorporation of the next correct nucleotide

To compare the ability of hPolк to extend mispaired primer termini by incorporating the correct next nucleotide (direct extension) or by template-primer misalignment, we used steady-state kinetics to measure the rate of nucleotide incorporation following a mismatched template-primer terminus. Appropriate DNA substrates were constructed to distinguish between these two modes of mispair extension (Table 1). DNA substrate 1, for example, contains a primer-terminal C.C mispair followed by a $G$ and an $A$ in the consecutive downstream template positions (Table 2). In this substrate, the $\mathrm{C} \cdot \mathrm{C}$ mispair can be extended by the direct incorporation of a C opposite the next $5^{\prime} \mathrm{G}$; alternatively, this mispair can be extended by template-primer misalignment, in which case the primer-terminal $C$ pairs with the next $5^{\prime} \mathrm{G}$, and

Table 1. DNA substrates used in this study

\begin{tabular}{|c|c|}
\hline $\begin{array}{l}\text { DNA } \\
\text { substrate }\end{array}$ & Sequence $^{\mathrm{a}}$ \\
\hline \multirow[t]{2}{*}{1} & $5^{\prime}-\cdots \mathrm{GCAC}$ \\
\hline & $3^{\prime}$-...CGTCGATCTTGAGAAGCACGTCCGTA \\
\hline \multirow[t]{2}{*}{2} & $5^{\prime}-\cdots \mathrm{GCAC}$ \\
\hline & 3'-...CGTCCATCTTGAGAAGCACGTCCGTA \\
\hline \multirow[t]{2}{*}{3} & $5^{\prime} \ldots \mathrm{GCAC}$ \\
\hline & 3'-...CGTCTATCTTGAGAAGCACGTCCGTA \\
\hline \multirow[t]{2}{*}{4} & $5^{\prime} \cdots \mathrm{GCAC}$ \\
\hline & 3' -...CGTCGTTCTTGAGAAGCACGTCCGTA \\
\hline \multirow[t]{2}{*}{5} & $5^{\prime} \cdots \mathrm{GCAC}$ \\
\hline & 3'-...CGTCGCTCTTGAGAAGCACGTCCGTA \\
\hline \multirow[t]{2}{*}{6} & $5^{\prime}-\cdots \mathrm{GCAC}$ \\
\hline & $3^{\prime}$-...CGTCGGTCTTGAGAAGCACGTCCGTA \\
\hline \multirow[t]{2}{*}{7} & $5^{\prime}-\cdots$ GCAGT \\
\hline & 3'-...CGTCGACGTTGAGAAGCACGTCCGTA \\
\hline \multirow[t]{2}{*}{8} & $5^{\prime} \ldots$ GCAGT \\
\hline & 3'-...CGTCGAGCTTGAGAAGCACGTCCGTA \\
\hline \multirow[t]{2}{*}{9} & $5^{\prime} \ldots$ GCAGT \\
\hline & 3'-...CGTCGATCTTGAGAAGCACGTCCGTA \\
\hline \multirow[t]{2}{*}{10} & $5^{\prime}-\cdots$ GCAGT \\
\hline & 3'-...CGTCGAGGTTGAGAAGCACGTCCGTA \\
\hline \multirow[t]{2}{*}{11} & $5 ' \ldots$ GCA \\
\hline & 3'-...CGTXATTCTTGAGAAGCACGTCCGTA \\
\hline \multirow[t]{2}{*}{12} & $5^{\prime} \cdots \mathrm{GCA}$ \\
\hline & 3'-...CGTXGTTCTTGAGAAGCACGTCCGTA \\
\hline \multirow[t]{2}{*}{13} & $5^{\prime} \cdots \mathrm{GCA}$ \\
\hline & 3'-...CGTXCTTCTTGAGAAGCACGTCCGTA \\
\hline \multirow[t]{2}{*}{14} & $5^{\prime}-\cdots \mathrm{GCAC}$ \\
\hline & 3'-...CGTXGTTCTTGAGAAGCACGTCCGTA \\
\hline \multirow[t]{2}{*}{15} & $5^{\prime}-\cdots \mathrm{GCAG}$ \\
\hline & 3'-...CGTXCTTCTTGAGAAGCACGTCCGTA \\
\hline \multirow[t]{2}{*}{16} & $5^{\prime} \cdots \mathrm{GCAT}$ \\
\hline & 3'-...CGTXATTCTTGAGAAGCACGTCCGTA \\
\hline
\end{tabular}

${ }^{a}$ For all of the DNA substrates, the upstream template-primer sequence is:

5'-CGACGATGCTCCGGTACTCCAGTGTAG $\cdots$;

3'-GCTGCTACGAGGCCATGAGGTCACATC $\cdots$.

$\mathrm{X}$ corresponds to an abasic site.

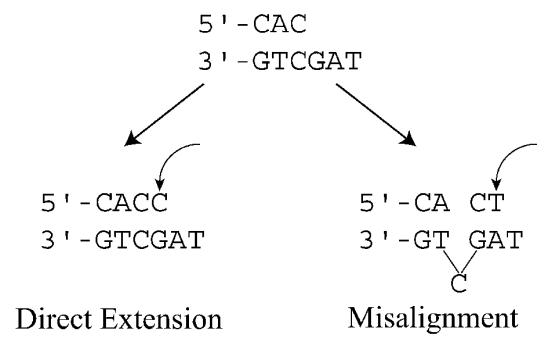

Figure 2. Two modes of mismatch extension by hPolк. (Left) In direct mismatch extension, following a primer-terminal mispair, the incoming dCTP (indicated by the curved arrow) base pairs with the correct templating base G. (Right) In extension by misalignment, the $\mathrm{C} \cdot \mathrm{C}$ mispair realigns so that the template $\mathrm{C}$ becomes extrahelical and the primer-terminal $\mathrm{C}$ pairs with the next template base G. This is followed by the pairing of the incoming dTTP (indicated by the curved arrow) with the subsequent complementary template base.

the misalignment is followed by the incorporation of a $\mathrm{T}$ opposite the next template base A (Fig. 2). hPolк was incubated with different concentrations of dATP, dTTP, $\mathrm{dCTP}$, or dGTP, and the rate of nucleotide incorporation plotted as a function of nucleotide concentration (Fig. 3). The $\mathrm{k}_{\text {cat }}$ and $\mathrm{K}_{\mathrm{m}}$ values for nucleotide incorporation were then determined from the best fit to the MichaelisMenten equation by using nonlinear regression. As shown in Figure 4, with this DNA substrate (\#1), only the $\mathrm{C}$ and $\mathrm{T}$ nucleotides were incorporated, and the efficiencies $\left(\mathrm{k}_{\mathrm{cat}} / \mathrm{K}_{\mathrm{m}}\right)$ of their incorporation were quite similar (Fig. 3; Table 2), indicating that, in this sequence context, the $\mathrm{C} \cdot \mathrm{C}$ mispair can be extended nearly equally well by direct extension or by misalignment. With DNA substrates 2 and 3 , on the other hand, in which the $\mathrm{C} \cdot \mathrm{C}$ mispair is followed by a $\mathrm{C}$ or a $\mathrm{T}$, respectively, in the next $5^{\prime}$ position in the template, the primer-terminal $\mathrm{C}$ is extended only by the incorporation of the next correct nucleotide, G or A, respectively (Table 2). Thus, in the absence of a complementary base in the next $5^{\prime}$ position in the template, the template-primer misalignment seen with substrate 1 does not occur.

Next, we examined the efficiency of hPolk in extending $\mathrm{C} \cdot \mathrm{C}$ primer termini by template-primer misalignment and by direct extension using DNA substrates 4,5 , and 6 , in which the base $5^{\prime}$ to the templating $G$ was modified to a $T$, a $C$, or a $G$, respectively. As shown in Figure 4, with DNA substrate 4, hPolk incorporates a C, which would occur by direct mispair extension, and also an A, incorporation of which would occur by templateprimer misalignment, with efficiencies of 0.1 and 0.03 , respectively (Table 2). Thus, in this case, direct mispair extension is approximately threefold more efficient than misalignment. On substrate 5, the nucleotides $\mathrm{C}$ and $\mathrm{G}$ are incorporated with the same relative efficiency (Fig. 4; Table 2), indicating that, in this sequence context, mispair extension by these two means occurs equally well. With substrate 6 , both modes of mispair extension would cause the insertion of a $\mathrm{C}$, as the two template bases $5^{\prime}$ to the mispair are Gs, and that is what is observed (Fig. 4; Table 2). In summary, for all four C.C 
Wolfle et al.

Table 2. Steady-state kinetic parameters for $C \cdot C$ mispair extension by Polк on undamaged DNA

\begin{tabular}{|c|c|c|c|c|c|c|}
\hline $\begin{array}{l}\text { DNA } \\
\text { substrate }\end{array}$ & Sequence & dNTP & $\mathrm{k}_{\mathrm{cat}}\left(\min ^{-1}\right)$ & $\mathrm{K}_{\mathrm{m}}(\mu \mathrm{M})$ & $\begin{array}{c}\mathrm{k}_{\mathrm{cat}} / \mathrm{K}_{\mathrm{m}} \\
\left(\mu \mathrm{M}^{-1} \mathrm{~min}^{-1}\right)\end{array}$ & $\mathrm{f}_{\mathrm{rel}}$ \\
\hline \multirow[t]{4}{*}{1} & CAC & dATP & n.d. & n.d. & $<0.0001$ & \\
\hline & GTCGAT & dTTP & $1.1 \pm 0.02$ & $65 \pm 3$ & 0.017 & 0.74 \\
\hline & & dCTP & $1.3 \pm 0.06$ & $56 \pm 7$ & 0.023 & \\
\hline & & dGTP & n.d. & n.d. & $<0.0001$ & \\
\hline \multirow[t]{2}{*}{2} & CAC & dGTP & $0.40 \pm 0.02$ & $9.1 \pm 2$ & 0.04 & \\
\hline & GTCCAT & dTTP & n.d. & n.d. & $<0.0001$ & \\
\hline \multirow[t]{2}{*}{3} & CAC & dATP & $0.34 \pm 0.02$ & $2.2 \pm 0.5$ & 0.15 & \\
\hline & GTCTAT & dTTP & n.d. & n.d. & $<0.0001$ & \\
\hline \multirow[t]{4}{*}{4} & CAC & dATP & $0.89 \pm 0.03$ & $30 \pm 4$ & 0.030 & \\
\hline & GTCGTT & dTTP & n.d. & n.d. & $<0.0001$ & 0.3 \\
\hline & & dCTP & $1.0 \pm 0.06$ & $10 \pm 3$ & 0.1 & \\
\hline & & dGTP & n.d. & n.d. & $<0.0001$ & \\
\hline \multirow[t]{4}{*}{5} & $\mathrm{CAC}$ & dATP & n.d. & n.d. & $<0.0001$ & \\
\hline & GTCGCT & dTTP & n.d. & n.d. & $<0.0001$ & 1.0 \\
\hline & & dCTP & $0.61 \pm 0.05$ & $18 \pm 6$ & 0.034 & \\
\hline & & dGTP & $0.34 \pm 0.09$ & $9.9 \pm 1.2$ & 0.034 & \\
\hline \multirow[t]{4}{*}{6} & CAC & dATP & n.d. & n.d. & $<0.0001$ & \\
\hline & GTCGGT & dTTP & n.d. & n.d. & $<0.0001$ & $\mathrm{~N} / \mathrm{A}$ \\
\hline & & dCTP & $0.57 \pm 0.042$ & $19 \pm 5$ & 0.03 & \\
\hline & & dGTP & n.d. & n.d. & $<0.0001$ & \\
\hline
\end{tabular}

$\left(\mathrm{f}_{\text {rel }}\right)$ The relative efficiency $\left(\mathrm{k}_{\mathrm{cat}} / \mathrm{K}_{\mathrm{m}}\right)$ of misalignment to direct extension; (n.d.) no nucleotide incorporation was detected.

mispair substrates $1,4,5$, and 6, mismatch extension is accomplished either directly through the incorporation of dCTP, or by incorporation of the nucleotide complementary to the base $5^{\prime}$ to the templating base via template-primer misalignment, and the two modes of extension occur with nearly equal efficiencies.

We also examined the extension of a $G \cdot T$ mispair in DNA substrates with different sequence contexts (Table 3). With DNA substrate 7 , only the incorporation of a T or a $\mathrm{G}$ nucleotide, which would occur by direct extension or by template-primer misalignment, respectively, was observed, and the efficiencies of extension by these two modes were nearly equivalent. On substrates 8 and 9, however, the extension of the $\mathrm{G} \cdot \mathrm{T}$ mispair by the direct incorporation of the next correct nucleotide was favored by $\sim 5$ - to 15 -fold over template-primer misalignment. On substrate 10, direct extension was approximately twofold more efficient than misalignment.

hPolк extends from the nucleotide opposite an abasic site only by template-primer misalignment

hPolк is unable to replicate through DNA lesions such as a cis-syn TT dimer, a (6-4) TT photoproduct, or an abasic site (Johnson et al. 2000a; Ohashi et al. 2000b). The inability of hPolk to replicate through these DNA lesions is primarily due to its highly inefficient incorporation of nucleotides opposite them. hPolк, however, is able to extend from a nucleotide inserted opposite the 3'T of the TT dimer by another DNA polymerase, and it does so by the incorporation of an A opposite the 5'T of the lesion (Washington et al. 2002). hPolk is unable to carry out the nucleotide incorporation or the extension step opposite the (6-4) TT lesion (Washington et al.
2002). DNA synthesis by hPolк stalls one nucleotide before an abasic site, indicating that this lesion, too, presents a block to nucleotide incorporation by this enzyme (Johnson et al. 2000a). hPolк, however, can weakly incorporate an A opposite an abasic site, but it is more than 250-fold less efficient at it than it is at incorporating an A opposite an undamaged T (Haracska et al. 2002b).

Kinetic studies with DNA polymerase $\beta$ have indicated that it skips an abasic site and incorporates the nucleotide that is complementary to the next $5^{\prime}$ template base (Efrati et al. 1997). In this dNTP-stabilized

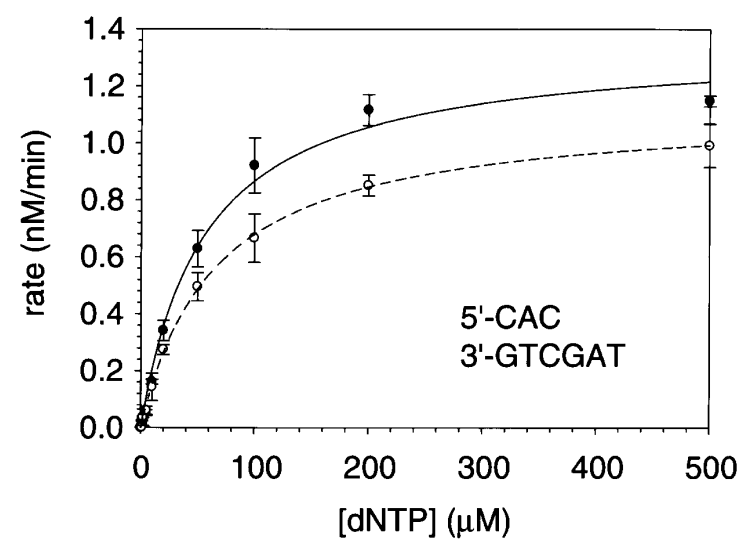

Figure 3. Steady-state kinetics of nucleotide incorporation by hPolk on DNA substrate 1 . The rate of $\operatorname{dCTP}(\bullet)$ and $\operatorname{dTTP}(O)$ incorporation following a C $\cdot \mathrm{C}$ primer-terminal mispair was graphed as a function of [dNTP]. The solid and broken lines represent the respective best fit to the Michaelis-Menten equation. The error bars represent the standard error of three experimental replicates. The steady-state parameters, $\mathrm{k}_{\mathrm{cat}}$ and $\mathrm{K}_{\mathrm{m}}$, are listed in Table 2. 


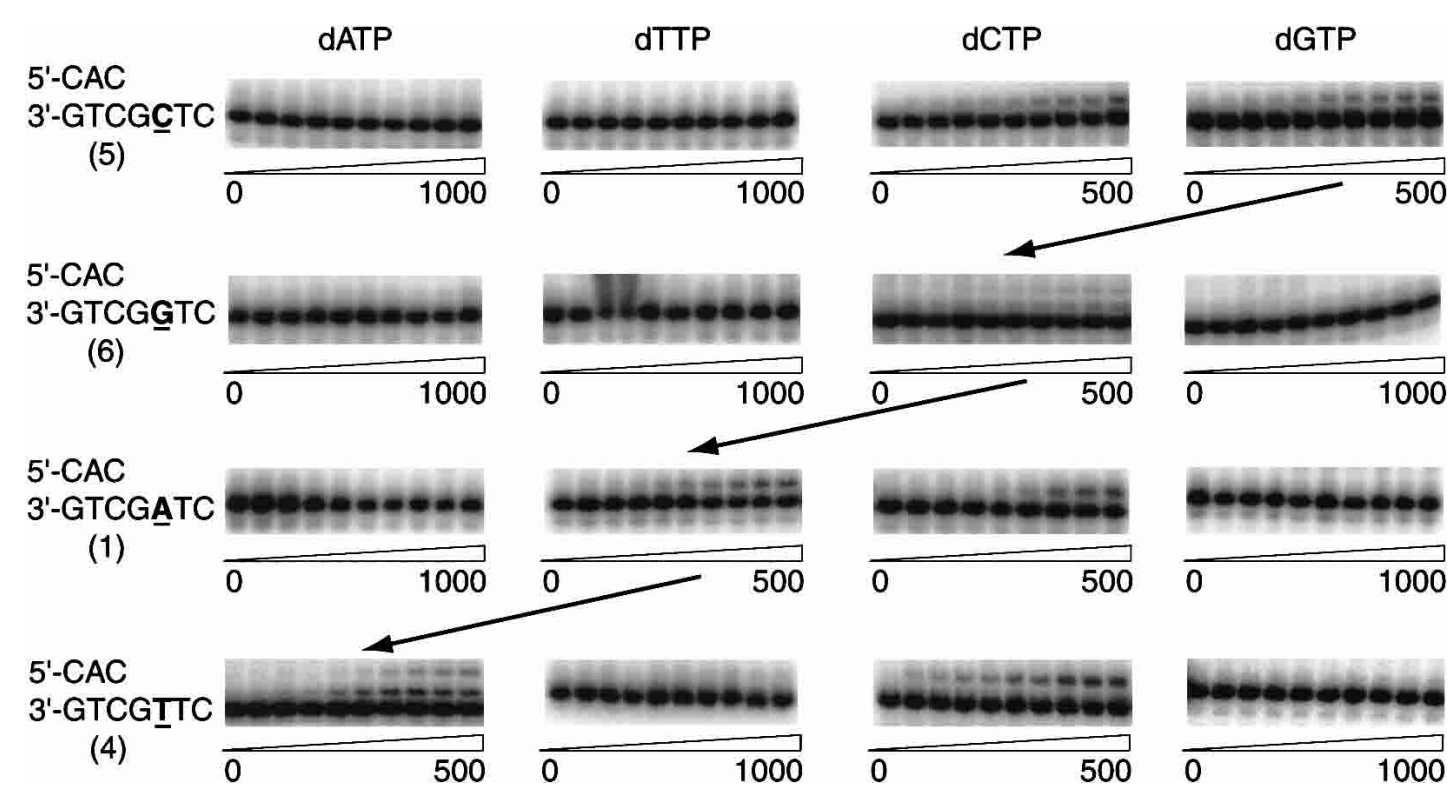

Figure 4. hPolk-catalyzed extension of a primer-terminal mispair by direct extension and by misalignment. The extension of a primer-terminal mispair by misalignment is inferred from the sequence specificity of nucleotides incorporated with various DNA substrates in which the base $5^{\prime}$ to the templating residue (bold and underlined) is varied. Incorporation of dCTP with each DNA substrate reflects direct extension of the mispair, and incorporation of the dNTP complementary to the base $5^{\prime}$ of the templating residue (indicated by diagonal arrows) reflects misalignment. dNTP concentration, in micromoles per liter, is indicated below each panel. The numbers below each DNA sequence refer to the substrates listed in Table 1 . The steady-state kinetic parameters $k_{\text {cat }}$ and $\mathrm{K}_{\mathrm{m}}$ are listed in Table 2 .

mode of frameshifting, the looped-out template abasic moiety is stabilized by the hydrogen bonding of the incoming dNTP bound in the polymerase active site to the complementary downstream base. Structural studies with S. solfataricus Dpo4 (Ling et al. 2001) and biochemical studies with E. coli Pol IV (Kobayashi et al. 2002) have also provided support for this means of frameshifting. To examine if hPolk uses such a frameshifting mechanism in bypassing an abasic site, we used DNA substrates 11-13, wherein a looping out of the template abasic site followed by the incorporation of the nucleotide complementary to the next $5^{\prime}$ template base would result in the incorporation of a $\mathrm{T}, \mathrm{C}$, or $\mathrm{G}$ nucleotide, respectively (Table 4). With all these DNA substrates, hPolk incorporated the nucleotides opposite the abasic site quite inefficiently; the A nucleotide, however, was incorporated preferentially over the others (Table 4).
From these observations, we conclude that hPolk does not use a dNTP-stabilized frameshifting mechanism at template abasic sites.

We have also examined the ability of hPolk to carry out dNTP-stabilized misalignment on nondamaged DNA templates, using the DNA substrate shown in Figure 1A. This substrate has an A . T primer-terminal base pair, a $\mathrm{C}$ as the templating base, and a $\mathrm{G}$ as the next $5^{\prime}$ template base. In this case, normal nucleotide incorporation would result in a dGTP being inserted opposite the template $\mathrm{C}$, and dNTP-stabilized misalignment would result in the enzyme skipping over the template $\mathrm{C}$ residue and incorporating a dCTP opposite the next $5^{\prime}$ template $\mathrm{G}$ residue. We found that only dGTP incorporation was detectible with this DNA substrate, and, given the detection limit of the assay, incorporation of the other dNTPs were at least 5000-fold lower than the

Table 3. Steady-state kinetic parameters for G-T mispair extension by Polк on undamaged DNA

\begin{tabular}{|c|c|c|c|c|c|c|}
\hline $\begin{array}{l}\text { DNA } \\
\text { substrate }\end{array}$ & Sequence & dNTP & $\begin{array}{c}\mathrm{k}_{\mathrm{cat}} \\
\left(\mathrm{min}^{-1}\right)\end{array}$ & $\begin{array}{c}\mathrm{K}_{\mathrm{m}} \\
(\mu \mathrm{M})\end{array}$ & $\begin{array}{c}\mathrm{k}_{\mathrm{cat}} / \mathrm{K}_{\mathrm{m}} \\
\left(\mu \mathrm{M}^{-1} \mathrm{~min}^{-1}\right)\end{array}$ & $\mathrm{f}_{\mathrm{rel}}$ \\
\hline \multirow[t]{2}{*}{7} & AGT & dTTP & $0.54 \pm 0.009$ & $190 \pm 9$ & 0.0028 & 0.96 \\
\hline & TCGACG & dGTP & $0.47 \pm 0.005$ & $177 \pm 8$ & 0.0027 & \\
\hline \multirow[t]{2}{*}{8} & AGT & dTTP & $2.2 \pm 0.05$ & $57 \pm 5$ & 0.039 & 0.2 \\
\hline & TCGAGC & dCTP & $1.5 \pm 0.09$ & $193 \pm 33$ & 0.0077 & \\
\hline \multirow[t]{2}{*}{9} & AGT & dTTP & $2.0 \pm 0.04$ & $43 \pm 4$ & 0.047 & 0.057 \\
\hline & TCGATC & dATP & $0.85 \pm 0.05$ & $314 \pm 50$ & 0.0027 & \\
\hline \multirow[t]{2}{*}{10} & AGT & dTTP & $0.28 \pm 0.02$ & $17.9 \pm 5$ & 0.016 & 0.54 \\
\hline & TCGAGG & $\mathrm{dCTP}$ & $0.74 \pm 0.02$ & $85.3 \pm 10$ & 0.0087 & \\
\hline
\end{tabular}

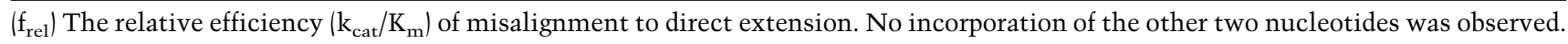


Wolfle et al.

Table 4. Steady-state kinetic parameters for nucleotide incorporation opposite an abasic site by Polк

\begin{tabular}{lllccr}
\hline $\begin{array}{l}\text { DNA } \\
\text { substrate }\end{array}$ & Sequence & dNTP & $\mathrm{k}_{\text {cat }}\left(\mathrm{min}^{-1}\right)$ & $\mathrm{K}_{\mathrm{m}}(\mu \mathrm{M})$ & $\begin{array}{c}\mathrm{k}_{\mathrm{cat}} / \mathrm{K}_{\mathrm{m}} \\
\left(\mu \mathrm{M}^{-1} \mathrm{~min}^{-1}\right)\end{array}$ \\
\hline 11 & GCA & dATP & $1.6 \pm 0.057$ & $235 \pm 27$ & 0.007 \\
& CGTXAT & dTTP & $0.090 \pm 0.0056$ & $212 \pm 55$ & 0.0004 \\
& & dCTP & $0.19 \pm 0.024$ & $409 \pm 180$ & 0.0005 \\
12 & dGTP & $0.10 \pm 0.0068$ & $281 \pm 62$ & 0.0004 \\
& GCA & dATP & $0.25 \pm 0.017$ & $269 \pm 47$ & n.d. \\
13 & dTTP & n.d. & n.d. & $<0.0001$ \\
& dCTP & n.d. & $321 \pm 88$ & 0.0001 \\
& GCA & dATP & $0.074 \pm 0.005$ & $216 \pm 17$ & 0.002 \\
& CGTXCT & dTTP & $0.44 \pm 0.013$ & n.d. & $<0.0001$ \\
& & dCTP & $0.069 \pm 0.0064$ & $295 \pm 96$ & 0.0002 \\
\hline
\end{tabular}

(n.d.) No nucleotide incorporation was detected; $(\mathrm{X})$ abasic site.

efficiency $\left(\mathrm{k}_{\mathrm{cat}} / \mathrm{K}_{\mathrm{m}}\right)$ of dGTP incorporation. We conclude from this that hPolk does not use a dNTP-stabilized mechanism of misalignment on nondamaged DNA.

Next, we used DNA substrates 14-16 to examine the ability of hPolk to extend from nucleotides placed opposite an abasic site (Table 5). With all these substrates, hPolk extends by template-primer misalignment and not by direct extension. For instance, with DNA substrate 14 , we observed only the incorporation of the A nucleotide (Fig. 5; Table 5), which would occur by the looping out of the abasic moiety followed by the pairing of primer-terminal $\mathrm{C}$ with the next $5^{\prime}$ template base $\mathrm{G}$ and the subsequent incorporation of an A opposite the next template base $\mathrm{T}$. In contrast, the lack of any $\mathrm{C}$ incorporation indicates the absence of direct extension (Fig. 5; Table 5). With substrates 15 and 16 also, only the incorporation of $\mathrm{A}$, which would occur by templateprimer misalignment, was observed (Table 5). Because of the inability to distinguish between direct extension and misalignment in the sequence context of DNA substrates 14-16, we did not examine the kinetics of extension from an A placed at the primer terminus directly opposite the template abasic site. However, we have confirmed the lack of direct extension from an A opposite an abasic site by hPolk using another sequence context.

\section{Discussion}

On undamaged DNA, hPolk is quite adept at extending mispaired termini by the incorporation of the next correct nucleotide (Washington et al. 2002). In copying undamaged DNA, however, Polк generates both base substitution and single-base deletion mutations (Ogi et al. 1999; Ohashi et al. 2000a). In this study, we have examined if hPolk could extend mispaired primer termini by using a template-primer misalignment mechanism, wherein the template base at the primer terminus "loops out," followed by the pairing of the primer-terminal base with the complementary 5 -template base and the incorporation of the nucleotide complementary to the next 5 '-template base (see Fig. 2). Such a mechanism would then result in single-base deletions. Using C.C and $\mathrm{G} \cdot \mathrm{T}$ primer-terminal mispairs, we show here that such a template-primer misalignment mechanism, in fact, is operative during DNA synthesis by hPolk, and in many of the sequence contexts, mispair extension by such a misalignment process is as frequent as that by the incorporation of the next correct nucleotide (direct extension).

Although most mismatches generated during normal DNA replication by Pols would be removed by its proofreading $3^{\prime} \rightarrow 5^{\prime}$ exonuclease, some of the mispaired termini could be refractory to this activity. In that case, the proficient ability of hPolk to extend mispaired primer termini by direct extension or by misalignment could contribute to the continued and efficient progression of the replication fork. However, we expect that, in this

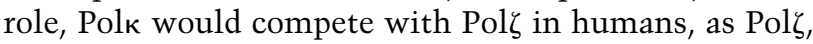
too, is an avid extender of mispaired primer termini (Johnson et al. 2000b). Genetic studies in yeast have indicated a role for Pol $\zeta$ in the generation of base substitution and deletion mutations, as inactivation of REV3, which encodes the catalytic subunit of Pol $\zeta$, decreases the rate of spontaneous single-base substitutions as well as single-base deletions by $\sim 60 \%$ (Roche et al. 1994; Kunz et al. 1998). These observations raise the possibility that Pol $\zeta$, too, can extend mispaired primer termini by using the template-primer misalignment mechanism described here for Polk, generating single-base deletions in the process. In that case, a mispaired primer terminus formed during normal DNA replication would be extended by Polk or by Polל, either directly or by misalignment.

Although hPolк can extend a mispaired primer terminus on undamaged DNA either directly or by misalignment, it extends from a nucleotide placed opposite an abasic site only by misalignment, wherein the base opposite the abasic site pairs with the complementary $5^{\prime}$ template base, and this misalignment is followed by the incorporation of a nucleotide complementary to the next 5 '-template base (see Table 5; Fig. 5). Although hPolк can incorporate an A opposite an abasic site, it is quite inefficient in doing so, and therefore, we do not expect it to make a significant contribution to AP bypass by a pro- 
Table 5. Steady-state kinetic parameters for extension from nucleotides opposite an abasic site by Polк

\begin{tabular}{lllccc}
\hline $\begin{array}{l}\text { DNA } \\
\text { substrate }\end{array}$ & Sequence & dNTP & $k_{\text {cat }}\left(\mathrm{min}^{-1}\right)$ & $\mathrm{K}_{\mathrm{m}}(\mu \mathrm{M})$ & $\begin{array}{c}\mathrm{k}_{\mathrm{cat}} / \mathrm{K}_{\mathrm{m}} \\
\left(\mu \mathrm{min}^{-1}\right)\end{array}$ \\
\hline 14 & CAC & dATP & $2.4 \pm 0.052$ & $313 \pm 20$ & 0.008 \\
& GTXGTT & dCTP & n.d. & n.d. & $<0.0001$ \\
15 & CAG & dATP & $2.1 \pm 0.044$ & $168 \pm 14$ & 0.01 \\
& GTXCTT & dGTP & n.d. & $<0.0001$ \\
16 & CAT & dATP & $1.6 \pm 0.057$ & $235 \pm 27$ & 0.007 \\
& GTXATT & dTTP & n.d. & n.d. & $<0.0001$ \\
\hline
\end{tabular}

(n.d.) No nucleotide incorporation was detected. Also, no incorporation of the other two nucleotides was observed; (X) abasic site.

cess in which it first incorporates the nucleotide opposite the abasic site and then extends from the incorporated nucleotide either directly or by misalignment (Ohashi et al. 2000b). However, in sequence contexts in which template-primer misalignment is possible, hPolk might contribute to AP bypass by extending from the nucleotide incorporated opposite the lesion site by an-

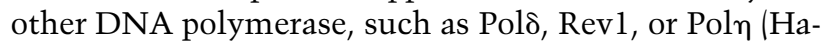
racska et al. 2001). Nevertheless, because of the highly proficient ability of Pol $\zeta$ to directly extend from nucleotides opposite an abasic site (Haracska et al. 2001), we expect this polymerase to make a much greater contribution to its bypass than hPolк.

The lack of direct extension from nucleotides opposite an abasic site by hPolк contrasts with its proficient ability to extend directly from nucleotides placed opposite DNA lesions such as a cis-syn TT dimer, an $O^{6}$-methylguanine, or an 8-oxoguanine lesion (Haracska et al. 2002a; Washington et al. 2002). Moreover, this extension is not predicated by the presence of a correct nucleotide opposite the lesion site. For example, hPolк efficiently extends from a G nucleotide opposite the 3'T of the TT dimer, from a $\mathrm{T}$ opposite an $\mathrm{O}^{6}$-methylguanine lesion, or from an A opposite an 8-oxoguanine lesion (Haracska et al. 2002a; Washington et al. 2002). This suggests that

\section{5 -CAC \\ 3'-GTXGIT}

(14)

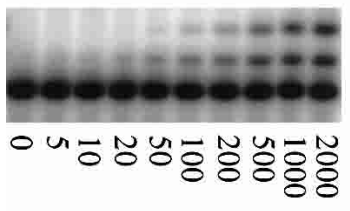

[dATP] $(\mu \mathrm{M})$

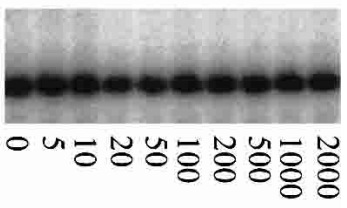

$[\mathrm{dCTP}](\mu \mathrm{M})$
Figure 5. hPolк-catalyzed extension from nucleotides opposite an abasic site by misalignment. The dATP and dCTP concentrations were varied from 0 to $2000 \mu \mathrm{M}$. (Left) On DNA substrate 14 , the incorporation of dATP opposite the downstream template T (bold and underlined) occurs via "looping out" of the abasic site and the subsequent pairing of the primer-terminal C with the next 5' template G. (Right) The lack of direct extension is illustrated by the absence of any dCTP incorporation. The steady-state kinetic parameters, $\mathrm{k}_{\mathrm{cat}}$ and $\mathrm{K}_{\mathrm{m} /}$ are listed in Table 5 .
hPolк can directly extend from a mispaired primer terminus irrespective of whether the template base at the primer terminus is damaged. From these observations, we infer that direct mispair extension by hPolк requires the presence of a base opposite the primer-terminal residue, whereas, in the absence of the said template base, only the misalignment mechanism is possible.

Although hPolk belongs to the DinB family, it differs from the other members of this family in its proficient ability to extend mispaired primer termini. For example, E. coli Pol IV misincorporates nucleotides with a frequency of $\sim 10^{-3}$ to $10^{-5}$, and it extends mispaired termini with about the same frequency (Kobayashi et al. 2002). We have found that the archaean Dpo4, too, is not an efficient extender of mismatched primer termini (W.T. Wolfle, R.E. Johnson, L. Prakash, and S. Prakash, unpubl.). hPolк differs also from these other polymerases in its virtual inability to carry out the dNTP-stabilized mode of misalignment, and, as we show here, hPolк can proficiently extend mispaired primer termini by using a different sort of template-primer misalignment mechanism.

The proficient ability of hPolк to extend mispaired primer termini directly or by template-primer misalignment suggests that its active site is particularly less constrained at the template-primer junction so that it can tolerate the geometric distortions conferred by mismatched base pairs or those resulting from templateprimer misalignment. In contrast to its proficient ability to extend mispaired primer termini, $\mathrm{f}_{\text {ext }}^{\mathrm{o}} \approx 10^{-1}$ to $10^{-2}$, hPolк misincorporates nucleotides with a frequency of $\sim 10^{-3}$ to $10^{-4}$. hPolk is also much less efficient at incorporating nucleotides opposite DNA lesions than at extending from nucleotides incorporated opposite the lesion site by another DNA polymerase (Haracska et al. 2002a; Washington et al. 2002). These properties of hPolk would suggest that its active site is much more constrained at the site of the templating base and the incoming dNTP than at the primer terminus.

In summary, in its proficient ability to extend mispaired primer termini either directly or by misalignment, hPolk has diverged significantly from its E. coli and archaean counterparts. Furthermore, it uses these two modes of mispair extension to different degrees, depending on whether the template base is present or absent at the primer terminus. These properties of hPolk distinguish it also from the other two human $\mathrm{Y}$ family 
polymerases, Poln and Poll, as neither of them is a proficient extender of mispaired primer termini, and additionally, these polymerases differ in their damage bypass abilities. These Y-family polymerases have thus become highly specialized, able to perform different tasks in replication and in damage bypass.

\section{Materials and methods}

\section{Nucleotides and DNA substrates}

Solutions of each dNTP (100 mM) were purchased from Roche Diagnostics and stored in aliquots at $-80^{\circ} \mathrm{C}$. Synthetic oligodeoxynucleotides were used to prepare the DNA substrates listed in Table 1. Substrates 1-6 contain a primer-terminal C $\cdot \mathrm{C}$ mispair, substrates $7-10$ contain a primer-terminal $\mathrm{G} \cdot \mathrm{T}$ mispair, and substrates $11-16$, contain a template strand abasic site. ${ }^{32} \mathrm{P}$ $5^{\prime}$-end labeled primers $(1 \mu \mathrm{M})$ were annealed to templates (1.5 $\mu \mathrm{M})$ in $50 \mathrm{mM}$ Tris $\cdot \mathrm{HCl}(\mathrm{pH} 7.5)$ and $100 \mathrm{mM} \mathrm{NaCl}$ by heating to $95^{\circ} \mathrm{C}$ for $2 \mathrm{~min}$, followed by slow cooling to room temperature.

\section{Protein expression and purification}

Yeast strain BJ5464 was transformed with plasmid pPOL42, which carries the gene encoding wild-type hPolk fused in frame with glutathione S-transferase. The protein was overexpressed and purified as described previously for Pol $\eta$ Washington et al. $2001 \mathrm{~b})$. Cleavage by PreScission protease resulted in an additional 7 amino acid leader sequence attached to the full-length

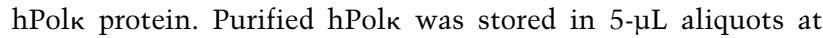
$-80^{\circ} \mathrm{C}$.

\section{Steady-state kinetic measurements}

The DNA polymerase assay contained $25 \mathrm{mM}$ Tris $\mathrm{HCl} / \mathrm{pH}$ 7.5), $5 \mathrm{mM}$ dithiothreitol, $0.1 \mathrm{mg} / \mathrm{mL}$ bovine serum albumin, 5 $\mathrm{mM} \mathrm{MgCl}_{2}, 50 \mathrm{nM}$ DNA, $1 \mathrm{nM}$ Polк, and various concentrations of $\mathrm{dNTP}$ in a range appropriate for $\mathrm{K}_{\mathrm{m}}$ determination. Values of the steady-state kinetic parameters $\mathrm{k}_{\text {cat }}$ and $\mathrm{K}_{\mathrm{m}}$ for nucleotide incorporation for all substrates, except 14-16, were determined as follows: The reactions were carried out for 10 min at $24^{\circ} \mathrm{C}$ and were quenched with the addition of four volumes of ice-cold $95 \%$ formamide loading dye and placed on ice. Product formation was monitored using $10 \%$ polyacrylamide gel electrophoresis ( $8 \mathrm{M}$ urea) and the respective gel band intensities were quantified using the PhosphorImager (Molecular Dynamics). The mean and standard error values for the rate of nucleotide incorporation at each nucleotide concentration were obtained from a set of three independent experiments and were used to determine the $\mathrm{k}_{\mathrm{cat}}$ and $\mathrm{K}_{\mathrm{m}}$ parameters from the best fit of the data to the Michaelis-Menten equation (Sigma Plot 7.0). For substrates 14-16, deoxynucleotide incorporation was measured at multiple time points for each nucleotide concentration, and the observed rate of nucleotide incorporation was determined by linear regression and used to determine $\mathrm{k}_{\text {cat }}$ and $\mathrm{K}_{\mathrm{m}}$. The efficiency of nucleotide incorporation $\left(\mathrm{k}_{\mathrm{cat}} / \mathrm{K}_{\mathrm{m}}\right)$ was determined and used to calculate the efficiency of misalignment relative to direct extension $\left(\mathrm{f}_{\text {rel }}\right)$.

\section{Acknowledgments}

This work was supported by National Institutes of Health Grant GM19261.
The publication costs of this article were defrayed in part by payment of page charges. This article must therefore be hereby marked "advertisement" in accordance with 18 USC section 1734 solely to indicate this fact.

\section{References}

Bebenek, K. and Kunkel, T.A. 1990. Frameshift errors initiated by nucleotide misincorporation. Proc. Nat. Acad. Sci. 87: 4946-4950.

Efrati, E., Tucco, G., Eritja, R., Wilson, S.H., and Goodman, M.F. 1997. Abasic translesion synthesis by DNA polymerase $\beta$ violates the "A-rule": Novel types of nucleotide incorporation by human DNA polymerase $\beta$ at an abasic lesion in different sequence contexts. J. Biol. Chem. 272: 2559-2569.

Goodman, M.F., Creighton, S., Bloom, L.B., and Petruska, J. 1993. Biochemical basis of DNA replication fidelity. Crit. Rev. Biochem. Mol. Biol. 28: 83-126.

Haracska, L., Prakash, S., and Prakash, L. 2000a. Replication past O6-methylguanine by yeast and human DNA polymerase $\eta$. Mol. Cell. Biol. 20: 8001-8007.

Haracska, L., Yu, S.-L., Johnson, R.E., Prakash, L., and Prakash, S. 2000b. Efficient and accurate replication in the presence of 7,8-dihydro-8-oxoguanine by DNA polymerase $\eta$. Nat. Genet. 25: 458-461.

Haracska, L., Unk, I., Johnson, R.E., Johansson, E., Burgers, P.M.J., Prakash, S., and Prakash, L. 2001. Roles of yeast DNA polymerases $\delta$ and $\zeta$ and of Rev1 in the bypass of abasic sites. Genes \& Dev. 15: 945-954.

Haracska, L., Prakash, L., and Prakash, S. 2002a. Role of human DNA polymerase $\kappa$ as an extender in translesion synthesis. Proc. Nat. Acad. Sci. 99: 16000-16005.

Haracska, L., Unk, I., Johnson, R.E., Phillips, B.B., Hurwitz, J., Prakash, L., and Prakash, S. 2002b. Stimulation of DNA synthesis activity of human DNA polymerase $\kappa$ by PCNA. Mol. Cell. Biol. 22: 784-791.

Johnson, R.E., Prakash, S., and Prakash, L. 1999. Efficient bypass of a thymine-thymine dimer by yeast DNA polymerase, Poln. Science 283: 1001-1004.

. 2000a. The human DINB1 gene encodes the DNA polymerase Pol1. Proc. Nat. Acad. Sci. 97: 3838-3843.

Johnson, R.E., Washington, M.T., Haracska, L., Prakash, S., and Prakash, L. 2000b. Eukaryotic polymerases $\iota$ and $\zeta$ act sequentially to bypass DNA lesions. Nature 406: 1015-1019.

Johnson, R.E., Washington, M.T., Prakash, S., and Prakash, L. 2000c. Fidelity of human DNA polymerase $\eta$. J. Biol. Chem. 275: 7447-7450.

Kim, S.-R., Maenhaut-Michel, G., Yamada, M., Yamamoto, Y., Matsui, K., Sofuni, T., Nohmi, T., and Ohmori, H. 1997. Multiple pathways for SOS-induced mutagenesis in Escherichia coli: An overexpression of $\operatorname{din} \mathrm{B} / \operatorname{din} \mathrm{P}$ results in strongly enhancing mutagenesis in the absence of any exogenous treatment to damage DNA. Proc. Nat. Acad. Sci. 94: 13792-13797.

Kobayashi, S., Valentine, M.R., Pham, P., O'Donnell, M., and Goodman, M.F. 2002. Fidelity of Escherichia coli DNA polymerase IV: Preferential generation of small deletion mutations by dNTP-stabilized misalignment. I. Biol. Chem. 277: 34198-34207.

Kokoska, R.J., Bebeneck, K., Boudsocq, F., Woodgate, R., and Kunkel, T.A. 2002. Low fidelity DNA synthesis by a Y family DNA polymerase due to misalignment in the active site. J. Biol. Chem. 277: 19633-19638.

Kunkel, T.A. and Soni, A. 1988. Mutagenesis by transient misalignment. J. Biol. Chem. 263: 14784-14789. 
Kunz, B.A., Ramachandran, K., and Vonarx, E.J. 1998. DNA sequence analysis of spontaneous mutagenesis in Saccharomyces cerevisiae. Genetics 148: 1491-1505.

Ling, H., Boudsocq, F., Woodgate, R., and Yang, W. 2001. Crystal structure of a Y-family DNA polymerase in action: A mechanism for error-prone and lesion-bypass replication. Cell 107: 91-102.

Masutani, C., Kusumoto, R., Yamada, A., Dohmae, N., Yokoi, M., Yuasa, M., Araki, M., Iwai, S., Takio, K., and Hanaoka, F. 1999. The XPV (xeroderma pigmentosum variant) gene encodes human DNA polymerase $\eta$. Nature 399: 700-704.

Mendelman, L.V., Petruska, J., and Goodman, M.F. 1990. Base mispair extension kinetics. Comparison of DNA polymerase $\alpha$ and reverse transcriptase. J. Biol. Chem. 265: 2338-2346.

Ogi, T., Kato Jr., T., Kato, T., and Ohmori, H. 1999. Mutation enhancement by DINB1, a mammalian homologue of the Escherichia coli mutagenesis protein DinB. Genes Cells 4: 607-618.

Ohashi, E., Bebenek, K., Matsuda, T., Feaver, W.J., Gerlach, V.L., Friedberg, E.C., Ohmori, H., and Kunkel, T.A. 2000a. Fidelity and processivity of DNA synthesis by DNA polymerase $\kappa$, the product of the human DINB1 gene. I. Biol. Chem. 275: 39678-39684.

Ohashi, E., Ogi, T., Kusumoto, R., Iwai, S., Masutani, C., Hanaoka, F., and Ohmori, H. 2000b. Error-prone bypass of certain DNA lesions by the human DNA polymerase $\kappa$. Genes \& Dev. 14: 1589-1594.

Prakash, S. and Prakash, L. 2002. Translesion DNA synthesis in eukaryotes: A one- or two-polymerase affair. Genes \& Dev. 16: $1872-1883$.

Roche, H., Gietz, R.D., and Kunz, B.A. 1994. Specificity of the yeast rev3 $\Delta$ antimutator and REV3 dependency of the mutator resulting from a defect $(\mathrm{rad} 1 \Delta)$ in nucleotide excision repair. Genetics 137: 637-646.

Streisinger, G., Okada, Y., Emrich, J., Newton, J., Tsugita, A., Terzaghi, E., and Inouye, M. 1966. Frameshift mutations and the genetic code. Cold Spring Harbor Symp. Quant. Biol. 31: 77-84.

Vaisman, A., Tissier, A., Frank, E.G., Goodman, M.F., and Woodgate, R. 2001. Human DNA polymerase ı promiscuous mismatch extension. J. Biol. Chem. 276: 30615-30622.

Washington, M.T., Johnson, R.E., Prakash, S., and Prakash, L. 2000. Accuracy of thymine-thymine dimer bypass by Saccharomyces cerevisiae DNA polymerase $\eta$. Proc. Nat. Acad. Sci. 97: 3094-3099.

. 2001a. Mismatch extension ability of yeast and human DNA polymerase $\eta$. J. Biol. Chem. 276: 2263-2266.

Washington, M.T., Prakash, L., and Prakash, S. 2001b. Yeast DNA polymerase $\eta$ utilizes an induced fit mechanism of nucleotide incorporation. Cell 107: 917-927.

Washington, M.T., Johnson, R.E., Prakash, L., and Prakash, S. 2002. Human DINB1-encoded DNA polymerase $\kappa$ is a promiscuous extender of mispaired primer termini. Proc. Nat. Acad. Sci. 99: 1910-1914.

Yu, S.-L., Johnson, R.E., Prakash, S., and Prakash, L. 2001. Requirement of DNA polymerase $\eta$ for error-free bypass of UVinduced CC and TC photoproducts. Mol. Cell. Biol. 21: 185188. 


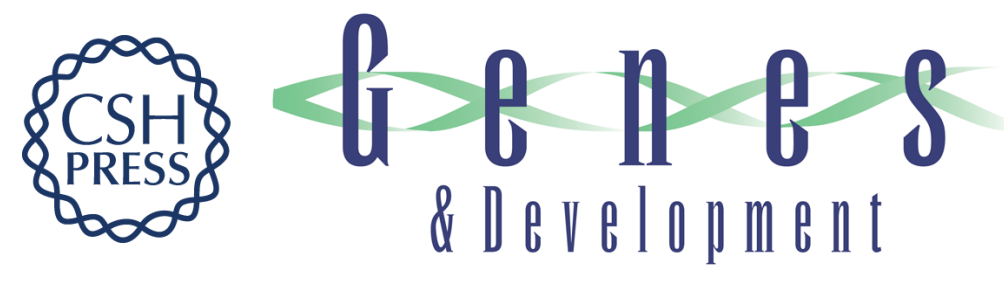

\section{Human DNA polymerase $\kappa$ uses template-primer misalignment as a novel means for extending mispaired termini and for generating} single-base deletions

William T. Wolfle, M. Todd Washington, Louise Prakash, et al.

Genes Dev. 2003, 17:

Access the most recent version at doi:10.1101/gad.1108603

References This article cites 32 articles, 25 of which can be accessed free at:

http://genesdev.cshlp.org/content/17/17/2191.full.html\#ref-list-1

License

Email Alerting Receive free email alerts when new articles cite this article - sign up in the box at the top

Service right corner of the article or click here.

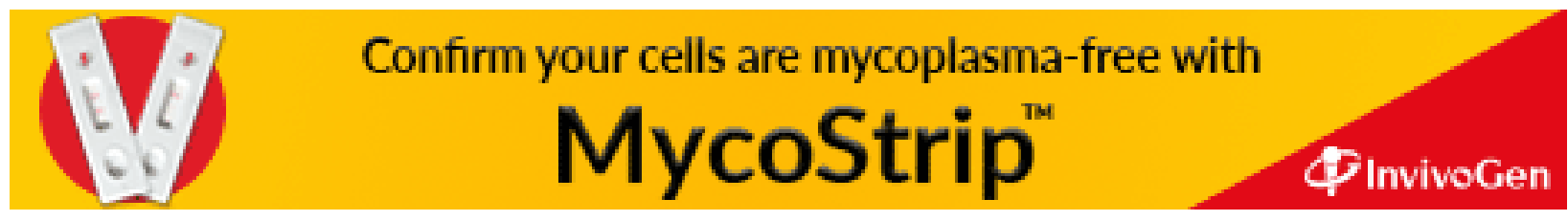

